\section{Milícias, Malícias e Delícias da Função Gerencial: o setor hoteleiro em foco}

"Military Services", Malices, and Delights of Management Role: the hospitality sector in focus

\author{
Kely César Martins de Paiva \\ Angelo Brigato Esther \\ Ana Carolina Rodrigues Pires ${ }^{3}$ \\ Marlene Catarina de Oliveira Lopes Melo ${ }^{4}$
}

\begin{abstract}
RESUMO: O objetivo deste artigo foi refletir sobre a função gerencial na hotelaria e, para tanto, realizou-se uma pesquisa de natureza qualitativa, com o uso da entrevista como principal instrumento de coleta de dados, em cuja análise utilizou-se a "análise de conteúdo". No referencial teórico, as peculia ridades dessa função foram discutidas em termos de "milícias" (atuação cotidiana, contradições, fragmentações, desafios), "malícias" (relações com outros atores sociais relevantes, como subordinados, chefias e clientes) e "delícias" (expectativas positivas, questões relacionadas a poder, status, realização), denotando suas particularidades no contexto organizacional. Após apresentar e analisar o conteúdo das 21 entrevistas realizadas, foram percebidas homogeneidades acerca dos relacionamentos dos gerentes com subordinados, superiores e clientes, e dificuldades com relação à compreensão de
\end{abstract}

1. Doutoranda e mestre em Administraçāo (UFMG/CEPEAD/NURTEG); professora e pesquisadora (Faculdade Novos Horizontes/NURTEG; Universidade FUMEC). Contato: Alameda das Orquídeas, 690 34000-000 - Nova Lima-mG; e-mail: serra.bh@terra.com.br.

2. Doutorando e mestre em Administraçāo (UFMG/CEPEA /NURTEG); professor e pesquisador (UFIF/FEA). Contato: Campus Universitário - Bairro Martelos -36036-330 - Juiz de Fora-MG; e-mail: abe@cepead. face.ufmg.br.

3. Bolsista de iniciaçāo científica (Faculdade Novos Horizontes/NURTEG); graduanda em Turismo e Gestāo em Hotelaria (Universidade fUMEC). Contato: Rua Alvarenga Peixoto, 1270 - 30180-121 Belo Horizonte-MG; e-mail: carolpires@gmail.com.

4. Doutora em Ciências das Organizaçōes (Université de Paris $\mathrm{x}$ - Dauphine, França); diretora acadêmica e coordenadora do Núcleo de Relaçōes de Trabalho e Tecnologias de Gestāo (Faculdade Novos Horizontes/NURTEG). Contato: Rua Alvarenga Peixoto, 1270 - 30180-121 - Belo HorizonteMG; e-mail: lenemelo@unihorizontes.br. seu papel e à capacitação profissional no setor. Ao final, apontaram-se aspectos pertinentes à academia e à função investigada, além de possibilidades de pesquisas.

PALAVRAS-CHAVE: função gerencial; gerente; hotel.

ABSTRACT: The objective of this article was to reflect on the management role in hospitality sector and, for in such a way, carried through a research of qualitative nature, with use of the interview as main instrument of collection of data, in whose analysis it was used "content analysis". In the theoretical referencial, the peculiarities of this function had been argued in terms of "military services" (daily performance, contradictions, spallings, challenges), "malices" (relations with other social actors, as subordinates, superiors and customers) and "delights" (positive expectations, questions about power, status, accomplishment), denoting its particularities in the organizational context. After to present and to analyze the content of the 21 interviews, they had been perceived homogeneities concerning the relationships of managers with subordinates, superiors and customers, and difficulties about the understanding of their paper and the professional qualification in the sector. To the end, pertinent aspects to the academy and the investigated function had been pointed, beyond possibilities of research.

KEYWORDS: management role; manager; hotel.

\section{Introdução}

O tema "função gerencial" tem instigado diversos autores em decorrência de vários fatores. O número considerável de perspectivas em que tal assunto pode ser trabalhado constitui-se ponto de enriquecimento, por um lado, e de discussão, por outro. A proposta deste artigo é refletir sobre a função gerencial em um setor em franco crescimento no Brasil e, em especial, em Minas Gerais: o de hotelaria. Para fins desse artigo, o termo "hotelaria" abraçará organizações como hotéis, motéis, apart-hotéis e flats.

Segundo Castelli (2001), o crescimento acelerado do turismo promoveu uma sensível expansão das empresas hoteleiras, decorrendo daí a exigência de formação de pessoal adequado aos diversos níveis e áreas de ocupação constituintes da estrutura organizacional peculiar de um hotel. $\mathrm{O}$ autor chamou a atenção para tal necessidade, independentemente do porte da empresa hoteleira, em virtude da fluidez e da organização dos serviços desse tipo de empreendimento. Os avanços tecnológicos deságuam em uma reestruturação do trabalho que também implica a questão da qualificação. Nesse sentido, Castelli (2001:36) afirmou que: 
A empresa hoteleira vem sofrendo, gradativamente, aperfeiçoamentos técnicos em seus equipamentos e instalaçōes, e mudanças relativamente ao seu posicionamento socioeconômico, face às oscilaçōes conjunturais. Conseqüentemente, o elemento humano, base do seu esquema operacional, deve estar devidamente preparado para assumir integralmente a empresa. (...) Além da formação técnico-científica, devem-se pôr em evidência também as qualidades humanas na formação do profissional especializado.

Dessa forma, atentar para a complexidade do profissional que atua nesse setor é fundamental para os resultados que a organização almeja. Castelli (2001: 38) afirmou que o sucesso desse tipo de empreendimento "repousa fundamentalmente no elemento humano qualificado", e sugere que profissionais competentes são os "que possuem: excelente qualificação pessoal, espírito de serviço, capacidade de recuperação e espírito de equipe" (Castelli, 2001: 38). Araújo (2003: 29) concordou com esse ponto de vista, sublinhando que formação profissional é imprescindível para a sedimentação de um caminho mais integrado e auto-sustentável, estendendo sua preocupação a outras organizações da indústria do turismo. Para esse autor:

(...) é visível que o nível dos colaboradores de uma organização turística, os treinamentos a que são submetidos, bem como seu histórico educacional, tornam-se componentes importantes, que impactam de forma decisiva a qualidade percebida do produto. Isso significa que o "valor" de um bem turístico, aos olhos dos clientes, pode ser influenciado - aumentado ou diminuído - pela performance de seus funcionários, ou seja, o "capital humano" que "produz" e "disponibiliza" o serviço.

Nesse contexto, a função gerencial assume contornos peculiares, uma vez que diz de um ritmo incansável; variedade, brevidade e fragmentação; preferência por questões atuais, específicas e não-rotineiras; preferência por meios de comunicação verbais em vez de escritos; uma rede de contatos internos e externos; e pesadas limitações, porém com algum controle sobre seu trabalho, em função da dependência de terceiros para que seus objetivos, e os da organização, sejam cumpridos (Guerrier, 2000).

Guerrier (2000:310) sublinhou que existem controvérsias acerca da exclusividade da natureza das habilidades de um gestor na área de hotelaria em relação a outros setores. A autora questionou também se a própria natureza das funções desempenhadas pelo gestor de hotelaria envolve habilidades mais técnicas e práticas ou empresariais e de gestão. Porém, de acordo com a autora, as mudanças e os avanços sociotecnológicos têm impactos diretos na atuação do gerente desse setor, obrigando-o a adaptar-se a contingências que nem sempre lhe deixarão em situação confortável: as tendências do setor indicam que:

(...) os gerentes precisarão ter conhecimento sobre administração de pessoal (mas haverá menos pessoal a administrar) e gerenciamento de clientes (e esse processo terá se tornado mais padronizado e sistematizado).

Ressalte-se que não se tem a pretensão de colocar um "ponto final" na discussão que vem sendo travada sobre a função gerencial. Pelo contrário: especificidades da própria função e do setor investigado abrem espaço para outras perguntas, o que, de fato, propicia um avanço no conhecimento. Para tanto, no que tange à metodologia da pesquisa, este trabalho pode ser caracterizado como de natureza qualitativa, tendo em vista que procurou obter entendimento de motivos e razões subjacentes a situações e fatos descritos pelos gerentes (Richardson, 1999; Cozby, 2003; Triviños, 1987).

Em termos de coleta de dados, priorizou-se a entrevista semi-estruturada, pois o objetivo era reconstruir processos de ação e experiências relacionadas às funções que o sujeito desempenha no seu dia-a-dia (Quivy \& Campenhoudt, 1998; Laville \& Dione, 1999). O roteiro inicial contemplava nove questões, cujo objetivo era levantar a visão do papel gerencial - de uma maneira geral e específica no setor investigado-, suas exigências, dificuldades e limitações, as relações com outros atores, conflitos, recompensas e desejos. No início de cada entrevista, dados demográficos do gerente eram levantados e, em seguida, dava-se prosseguimento à entrevista propriamente dita, cuja duração média foi de 45 minutos.

Contou-se também com a observação direta durante o período de coleta, que durou cerca de três semanas. Foram utilizados guias turísticos da BELOTUR e listas telefônicas locais para levantar o público-alvo, disperso pela cidade de Belo Horizonte (Minas Gerais), e 51 organizações foram contatadas (26 hotéis, três motéis, 13 apart-hotéis e nove flats). Destas, 24 agendaram entrevistas e três pediram para que se enviasse o roteiro de entrevista por e-mail (posteriormente, um respondeu, negando, e dois não deram resposta). Dado que um gerente não compareceu no horário marcado, dois cancelaram e um se recusou a dar entrevista (alegando problemas anteriores com pesquisas acadêmicas), $21^{5}$ entrevistas foram realizadas de fato. Note-se que, em duas destas, o proprietário da empresa dispensou o gerente e concedeu, ele próprio, a entrevista, e em outra não foi permitida a gravação. Tais presenças dos proprietários serão retomadas na apresentação e na

5. Esse número poderia ser elevado para 25 , já que um dos proprietários era dono de quatro motéis e um gerente administrava dois hotéis. 
análise dos dados, em virtude dos aspectos importantes que evidenciaram. Assim, apenas 20 entrevistas foram gravadas e transcritas, e posteriormente analisadas à luz da técnica de "análise de conteúdo" (Triviños, 1987; Bardin, 1977; Minayo, 1992; Richardson, 1999), comumente usada em pesquisas dessa natureza.

Em termos da estrutura do artigo, as referências conceituais da função gerencial foram subdivididas em termos de "milícias" (características da atuação cotidiana, contradições, fragmentações e desafios), "malícias" (foco nas relações com outros atores sociais relevantes, como subordinados, chefias e clientes) e "delícias" (expectativas positivas, questões relacionadas a poder, status, realização) por conta dos contornos particulares expostos anteriormente. Em seguida, os dados coletados - demográficos, entrevistas com os gerentes e entrevistas com os proprietários - foram apresentados e analisados, permitindo que considerações fossem sublinhadas e, ao final, apontadas questões relacionadas à academia e à função investigada, além de possibilidades de pesquisas posteriores.

\section{A função gerencial: suas milícias, malícias e delícias}

O trabalho gerencial vem sendo alvo de estudos há algum tempo e, embora exista algum consenso sobre seus papéis e funções, ainda não se tem uma unanimidade quanto ao que, de fato, significa ser gerente, se há um perfil ideal universal e assim por diante. Ciente de tais dificuldades, vários estudos vêm sendo desenvolvidos, com o intuito de conhecer melhor o trabalho do gerente.

No campo da administração, um dos trabalhos pioneiros foi desenvolvido por Taylor (1970). Embora não trate exatamente da função gerencial, sua obra esboça parte do trabalho do gerente ao propor seus quatro princípios básicos de administração. Além disso, em função de sua proposta de divisão do trabalho, Taylor (1970) sugere a necessidade de estabelecer a chamada supervisão funcional para controlar a execução da tarefa dos subordinados.

Quem efetivamente começou a se preocupar com a questão da gerência foi Fayol (1990), ao propor as chamadas funções da administração e os 14 princípios que a empresa deve seguir. Dentre esses princípios destacou-se a busca por disciplina dos empregados, subordinação dos interesses individuais aos organizacionais e espírito de grupo. Fayol (1970) estabeleceu as funções (hoje consideradas clássicas) da administração: previsão, organização, comando, coordenação e controle. O administrador da época de Fayol era aquele que ocupava um cargo formal na burocracia estudada por Weber, ou seja, o indivíduo que detinha uma especialização e a autoridade formal, ou seja, o poder legítimo que o cargo lhe imputava (Weber, 1982).
O sistema "taylorista" foi alvo de muitas críticas, em razão de considerar o indivíduo uma peça de máquina, e não um ser humano dotado de necessidades, expectativas e desejos (Braverman, 1981; Morgan, 1996). Tais críticos procuravam, de certo modo, "humanizar" um pouco mais o ambiente organizacional. Um dos grandes expoentes dessa linha foi Rensis Likert. Nos anos 1960, ele percebeu o aumento da concorrência no mercado norte-americano e deu-se conta de que as organizações já não obtinham a mesma eficiência de antes com o sistema taylorista-fordista atrelado às idéias de Fayol. Sua crítica apontava a falência do gerentebasicamente autoritário, que pressupunha meramente a obediência às suas ordens. Em contrápartida, Likert formulou um sistema de administração que incluía as seguintes variáveis: natureza das forças motivacionais, natureza do processo de comunicação, natureza do processo influência-interação, natureza do processo decisório, natureza do estabelecimento de metas, natureza dos processos de controle e características do desempenho (Likert, 1971).

A partir da combinação de características das variáveis acima, Likert propôs seus quatro sistemas de administração: autoritário forte, autoritário benevolente, participativo consultivo e participativo de grupo. Em função de suas constatações, Likert (1971) defendia o perfil de participativo de grupo como sendo o ideal, devendo a gerência criar grupos de alta eficiência.

Drucker (1967), por sua vez - a exemplo da preocupação de Likert com o aumento da concorrência -, enfatizou a questão da eficácia, afirmando que aos trabalhadores manuais bastava a eficiência, enquanto para o trabalho gerencial, a eficácia era o elemento central, definida por ele como “(...) a tecnologia específica do trabalhador com conhecimento dentro de uma organização" (Drucker, 1967:2). Ao mesmo tempo, o autor associava o conceito ao alcance de resultados, ao "fazer as coisas certas".

Também merece destaque o trabalho de Barnard (1971), que, tendo exercido um cargo executivo durante muito tempo em sua carreira, propôs algumas funções para o ocupante do cargo: manutenção das comunicações na organização; asseguramento de serviços essenciais dos indivíduos; formulação de propósitos e objetivos. Em conjunto, Barnard considerou-as constituindo o processo administrativo, desempenhado dentro da organização, a qual ele via como um sistema cooperativo racional.

Na década de 1970, Mintzberg analisou o trabalho de cinco executivos de uma empresa e acabou por identificar dez papéis agregados em três categorias, originados da autoridade formal e do status: os papéis interpessoais (imagem de chefe, líder e contato) dando origem aos papéis informacionais (monitor, disseminador e porta-voz), e estes dois capacitando o executivo a desempenhar os papéis decisoriais (empreendedor, manipulador de distúrbios, alocador de re- 
cursos e negociador). O autor procurou demonstrar que, ao contrário da imagem que se tinha, os executivos trabalhavam num ritmo inexorável, suas tarefas eram breves, variadas e descontínuas, e eles estavam firmemente orientados para a ação; - trabalho administrativo envolvia execução de rotinas, incluindo rituais e cerimônias; os executivos preferiam a mídia verbal, principalmente telefonemas e reuniões; os programas de executivos para organizar o tempo, processar informações e tomar decisões estavam em suas cabeças, havendo uso de julgamento e de intuição (Mintzberg, 1986).

Na mesma época (década de 1970), Robert Katz apontou diferenças entre as qualidades requeridas para os gerentes nos diversos níveis hierárquicos organizacionais. $\mathrm{O}$ autor definiu habilidade como uma capacidade que pode ser desenvolvida, que se manifesta no desempenho e não apenas em potencial ou na capacidade de transformar conhecimento em ação (Katz, 1986). As habilidades possuiriam uma importância relativa, conforme o nível hierárquico em que se situasse o gerente, e Katz (1986) definiu-as como habilidades conceituais, humanas e técnicas: a primeira relacionando-se com conhecimento organizacional, visão da organização como um todo; a segunda dizendo respeito ao domínio de habilidades de relacionamento com os subordinados; e a terceira tendo a ver com a conhecimento específico das atividades executadas. Assim, o nível de supervisão (baixa gerência) precisaria deter mais habilidade técnica que conceitual em relação ao administrador de nível mais alto. O nível médio necessitaria de uma dose mais equilibrada das três habilidades, sendo que a necessidade humana possuiria uma importância alta em todos os níveis.

Outro estudo emblemático sobre a função gerencial foi o de Hill (1993), que salientou seu caráter multifacetado tanto no que diz respeito aos meios e processos nos quais o gerente desenvolve suas atividades produtivas, como também aos fins e expectativas às quais deve (ou pelo menos tenta) estar atento e atingir. Em termos de processo, a autora sublinhou as características de variedade e fragmentação do trabalho gerencial em face da sua dependência em relação aos outros atores sociais, principalmente os subordinados. Atingir objetivos, nesse sentido, torna-se tarefa árdua, pois deve conjugar esforços variados: psicológicos, técnicos e outros, ligados às relações de poder. Porém, suprir expectativas de públicos diversos exige flexibilidade (uma "malícia" que a experiência proporciona), tornando o papel do gerente uma verdadeira arte: os superiores focam em resultados e redes de relacionamento; os subordinados, em condições de trabalho, políticas remuneratórias etc.; os clientes, em produtos e/ou serviços com qualidade; a família, em dedicação; ele próprio, em crescimento profissional, social, psicológico etc. (Hill, 1993).

Outro aspecto a que Hill (1993) deu ênfase diz respeito às relações de poder e como estas são delineadas à medida que o sujeito vai se adequando às responsa- bilidades e autoridade inerentes ao cargo e, ao mesmo tempo, organizando-se psiquicamente para seus "sucessos" e "fracassos". Ações bem-sucedidas tornam-se pontos fortes de apoio, enquanto as malsucedidas enfatizam a aprendizagem contínua: ambas, porém, servem de referência para o futuro. Questões relacionadas à comunicação também foram discutidas pela autora, que percebeu, assim como Barnard (1971), a importância desse processo não apenas para o trânsito das in formações e para os processos de tomada de decisão, mas também a partir de sua colaboração para a legitimação da autoridade inerente ao cargo.

Já no Brasil, Motta (1995) apresentou uma excelente compilação das principais dimensões do trabalho do dirigente (gerente): dimensão organizacional, que se relaciona com conhecer o contexto em que a organização atua, sua missão, seus objetivos estratégicos e sua cultura; dimensão interpessoal, que implica possuir habilidades de interação e de comunicação; e dimensão individual, que diz respeito a certas qualidades individuais que o gerente deve possuir, tais como iniciativa e integridade.

A despeito de tantos estudos, em pesquisas recentes sobre o gerente e a função gerencial no Brasil, Melo $(1995,1999)$ apontou a ausência de consenso sobre o perfil gerencial mesmo entre os gerentes. De fato, há uma grande diversidade de opiniões sobre os desafios que se impõem aos gerentes e quais são exatamente as características e habilidades que eles precisam ter para exercer suas funções. Retomando as questões relacionadas a poder, a autora apontou controvérsias em torno do papel gerencial: o crédito atribuído a esse profissional pelo desempenho da organização (“delícias”...), e as acusações sobre sua contribuição para a manutenção das relações de poder e de seu trabalho, a favor da regulação das contradições da vida corporativa ("milícias”...). De acordo com Melo (1995: 18), essa questão envolve um duplo papel do gerente: "ser assalariado e representante do empregador ao mesmo tempo".

A função gerencial configura-se, dessa forma, em algo complexo, de difícil adaptação e manutenção.

\section{Apresentação e análise dos dados}

A apresentação dos dados coletados dar-se-á em três blocos, a saber: dados demográficos dos gerentes, entrevistas dos gerentes e entrevistas dos proprietários.

Dados demográficos dos gerentes

Em termos de dados demográficos, cinco aspectos foram considerados quando das entrevistas com gerentes e proprietários entrevistados. O primeiro diz respei- 
to à faixa etária: a maior parte dos entrevistados (6) encontrava-se entre 31 e 35 anos de idade; dois tinham menos de 25 anos; cinco estavam entre 26 e 30 anos; um, entre 36 e 40 anos; quatro, entre 41 e 45 anos; um, entre 46 e 50 anos; e dois com mais de 50 anos de idade. Quanto ao sexo, a maioria dos respondentes era do sexo masculino (13, incluindo os proprietários), e dessa forma, oito do sexo feminino. No que tange à formação acadêmica, um possuía o segundo grau; três, o segundo grau técnico (sendo dois em Hotelaria e um em Contabilidade); três contavam com superior incompleto (um em Administração; um em Ciências Contábeis; e outro em Turismo e Gestão em Hotelaria); e 14 apresentavam nível superior completo (três em Turismo - sendo que um também era formado em Letras; quatro em Administração - sendo que um também tinha concluído o curso de Ciência da Computação; três em Ciências Contábeis; um em Economia; um em Ciências Sociais; um em Publicidade e Propaganda; e um em Comunicação Social). Com relação ao cargo, 13 dos entrevistados ocupavam o cargo de "gerente geral"; dois eram "gerentes de vendas"; dois, "gerentes administrativos / operacionais e financeiros"; um, "gerente de hospedagem"; um, "gerente de recepção"; e dois eram proprietários. Por fim, levou-se em consideração a categoria da empresa investigada dentro do setor de hotelaria: dentre os 21 estabelecimentos, dez eram hotéis; três, apart-hotéis; cinco, flats; e três, motéis.

\section{Entrevistas com os gerentes}

A Tabela 1 apresenta a percepção dos entrevistados quanto ao que significava ser gerente. Observou-se que não houve uma unanimidade na definição; ao contrário, cada um dos entrevistados enfocou um aspecto que envolvia a função gerencial. Isso confirmou o que a literatura vem afirmando, ou seja, que as atividades dos gerentes são diversificadas e abrangentes, carregadas de nuances. Os dados implicam não haver, portanto, uma definição precisa, o que de certo modo dificulta a criação de uma imagem clara sobre o que significa ser gerente atualmente.

No entanto, é interessante ressaltar que dois entrevistados utilizaram o termo "fiscalizar": uma vez, em relação à qualidade; outra, no que tange aos funcionários. Embora não tenha havido uma unanimidade de definição, os entrevistados abordaram a função gerencial de forma ampla e compatível com o que normalmente se espera da atuação de gerentes. Em outras palavras, as respostas consideraram o ambiente de negócios, os setores da empresa, os empregados e os clientes. No entanto, o uso da expressão "fiscalizar" remete a uma abordagem conservadora e relativamente ultrapassada, pois implica uma imagem do empregado baseada em alguém que não merece confiança.
Tabela 1. Respostas a "ser gerente atualmente"

\begin{tabular}{|c|c|c|}
\hline Respostas a "ser gerente atualmente" & Entrevistados & $\begin{array}{c}\text { Total de } \\
\text { entrevistados }\end{array}$ \\
\hline $\begin{array}{l}\text { Saber identificar a necessidade do cliente e } \\
\text { dar lucro para a empresa }\end{array}$ & E1 & 1 \\
\hline Fiscalizar os funcionários & E2 & 1 \\
\hline Administrar conflitos e próblemas & E3 & 1 \\
\hline Fazer a equipe atingir os objetivos & E4 & 1 \\
\hline Envolver-se com todos os setores & E5 & 1 \\
\hline $\begin{array}{l}\text { Comandar e distribuir tarefas para os } \\
\text { subordinados }\end{array}$ & E7 & 1 \\
\hline Liderar pessoas & E8 & 1 \\
\hline $\begin{array}{l}\text { Ter visão globalizada e identificar } \\
\text { oportunidades de negócios }\end{array}$ & E9 & 1 \\
\hline Administrar todos os serviços & E10 & 1 \\
\hline Visão ampla do negócio & E11 & 1 \\
\hline Acompanhar os processos & E12 & 1 \\
\hline Saber e fazer de tudo um pouco & E13 & 1 \\
\hline $\begin{array}{l}\text { Ser flexível e conhecer profundamente o } \\
\text { mercado }\end{array}$ & E14 & 1 \\
\hline Capacidade de lidar com a concorrência & E15 & 1 \\
\hline Dinamismo e competência no que faz & E16 & 1 \\
\hline Fiscal da qualidade & E17 & 1 \\
\hline Estar a par de tudo que cerca o seu meio & E18 & 1 \\
\hline
\end{tabular}

Fonte: Dados da pesquisa 
A Tabela 2, embora direcionada para a atuação gerencial na hotelaria, corrobora as respostas anteriores, ainda que com alguma diferença para a Tabela 1. A ênfase, aqui, recai mais sobre o cliente e o negócio.

Pode-se destacar a fala de E18, que chama a atenção para o herói:

Ser gerente na área de turismo é ser um herói, principalmente no Brasil, que não dá valor nenhum a esta área (...) (E18).

A fala acima corrobora a visão dos gerentes sobre o turismo no país, explicitada nas respostas alinhadas na Tabela 3.

Tabela 2. Respostas a "ser gerente na área de turismo - hotelaria"

\begin{tabular}{l|c|c}
\hline $\begin{array}{l}\text { Respostas a "ser gerente na área de turismo- } \\
\text { hotelaria" }\end{array}$ & Entrevistados & $\begin{array}{c}\text { Total de } \\
\text { entrevistados }\end{array}$ \\
\hline Prestar bons serviços & E4, E5 & 2 \\
\hline Gerenciar pessoas & E12, E13 & 2 \\
\hline Ser uma pessoa flexível e com muito "jogo de cintura" & E2 & 1 \\
\hline Gerir a organização como um todo & E3 & 1 \\
\hline Buscar qualidade de atendimento & E6 & 1 \\
\hline Estar ciente das inovações e dos concorrentes & E7 & 1 \\
\hline Ter visão cultural e geográfica do país & E9 & 1 \\
\hline Transformar conhecimento em oportunidade de & E9 & 1 \\
\hline negócios & E10 & 1 \\
\hline Conhecer a região e o mercado & E11 & 1 \\
\hline Fazer o máximo de contato possível & E15 & 1 \\
\hline Exercer com criatividade o dia-a-dia & E16́ & 1 \\
\hline
\end{tabular}

Fonte: Dados da pesquisa.
Tabela 3. Respostas a "percepção do turismo - hotelaria no Brasil"

\begin{tabular}{l|c|c}
\hline $\begin{array}{l}\text { Respostas a "percepção do turismo- } \\
\text { hotelaria no Brasil }\end{array}$ & Entrevistados & $\begin{array}{c}\text { Total de } \\
\text { entrevistados }\end{array}$ \\
\hline Pouco incentivo do governo & E5*, E8, E10, E14, E16 & 5 \\
\hline Falta infra-estrutura & E2, E9, E10 & 3 \\
\hline Em desenvolvimento & E8, E12, E16 & 3 \\
\hline Grande importância econômica: emprego e renda & E1, E16, E17 & 3 \\
\hline Pouco explorado & E3, E13 & 2 \\
\hline Falta divulgação & E2 & 1 \\
\hline Qualidade média & E6 & 1 \\
\hline Poucos Estados levam a sério & E7 & 1 \\
\hline Deveria haver parceria entre o público e o privado & E13 & 1 \\
\hline Bem resolvido, faltam ajustes & E19 & 1 \\
\hline
\end{tabular}

* Referiu-se, neste caso, apenas a Belo Horizonte.

Fonte: Dados da pesquisa. Referiu-se, neste caso, apenas a Belo Horizonte.

Em sua maioria, os entrevistados consideraram que não há incentivo do governo, que falta infra-estrutura e exploração, mas que, no entanto, o turismo está em crescimento e possui potencial para crescimento quase indefinido. Alguns depoimentos foram significativos quanto a isso.

Bom, eu acho que ele é muito pouco explorado... muito pouco valorizado. É um setor que tem um potencial muito grande, mas é muito pouco explorado (E3). O turismo no Brasil está em desenvolvimento, né? (...) Porém, precisa de uma ação mais efetiva dos órgãos governamentais no que se refere a incentivos para o crescimento do turismo, mas a gente tem (...) uma visão otimista em relação do turismo no Brasil. Ele está em crescimento (E8).

O turismo de um modogeral é um (...) acho que um dos setores tanto da economia, tanto da indústria... que sempre está em expansão e sempre buscando novos caminhos, eu acho que o turismo é um (...) é algo [em] que o governo tem que investir bastante porque é um grande gerador de empregos e é uma coisa (...) é o segmento que tem bastante importậncia na economia do Brasil hoje (E16).

De modo a atuar no setor de turismo e hotelaria, os gerentes foram indagados sobre as principais exigências que lhes eram impostas para o desempenho da função gerencial (Tabela 4). 
Tabela 5. Respostas a "pontos positivos de ser gerente na empresa"

\begin{tabular}{|c|c|c|}
\hline $\begin{array}{l}\text { Respostas a "pontos positivos de ser gerente na } \\
\text { empresa" }\end{array}$ & Entrevistados & $\begin{array}{c}\text { Total de } \\
\text { entrevistados }\end{array}$ \\
\hline Autonomia / independência / liberdade & $\begin{array}{l}\text { E1, E2, E3, E4, E7, E8 } \\
\text { E10, E14, E15, E17, E19 }\end{array}$ & 11 \\
\hline Acesso à diretoria & E9, E12, E18 & 3 \\
\hline Satisfação do cliente & E6, E16 & 2 \\
\hline Gama de conhecimentos & E5 & 1 \\
\hline Lidar com vários tipos de pessoas & E5 & 1 \\
\hline Imagem da empresa conquistada & E7 & 1 \\
\hline Empresa local pequena e familiar & E9 & 1 \\
\hline Expor os pontos de vista & E11 & 1 \\
\hline Flexibilidade & E12 & 1 \\
\hline Seriedade e espírito empreendedor da diretoria & E13 & 1 \\
\hline Investimento em recursos humanos & E14 & 7 \\
\hline
\end{tabular}

Fonte: Dados da pesquisa.

As pressões verificadas sobre a atuação do gerente são de variadas ordens e, na hotelaria, não se foge a essa "regra", pelo que se pode observar nas transcrições dos depoimentos a seguir:

No nosso caso, as coisas têm que ser resolvidas ali na hora, tá? (E7).

Porque, se você tivesse é (...) com tudo muito bem delimitado, você tivesse apenas que executar. Mas nāo, você tem que, além de executar, você tem que criar, tem que construir um hotel novo a cada dia (E8).

Eu costumo dizer que o gerente é a salsicha do cachorro-quente, né? Quê que acontece com a salsicha do cachorro-quente? Ela está entre duas partes de um pāo, né? O gerente ele está o quê? Ele está entre duas partes da empresa, entre a direçāo, que está em cima, e a classe de funcionários, que está abaixo. Entāo, às vezes, é bomba de um lado e do outro, você entendeu? (E13).

Entāo você tem que trabalhar sempre no limite (E16).
Tabela 6. Respostas a "dificuldades no exercício do papel gerencial nessa empresa"

\begin{tabular}{|c|c|c|}
\hline $\begin{array}{l}\text { Respostas a "dificuldades no exercício do papel } \\
\text { gerencial nessa empresa" }\end{array}$ & Entrevistados & $\begin{array}{c}\text { Total de } \\
\text { entrevistados }\end{array}$ \\
\hline Restrições financeiras / planejamento & $\begin{array}{l}\text { E5, E9, E10, E11, E12, } \\
\text { E16 E17, E18 }\end{array}$ & 8 \\
\hline $\begin{array}{l}\text { Promover "espírito de equipe" / integração entre } \\
\text { áreas, conflito entre pessoas / áreas }\end{array}$ & $\begin{array}{l}\text { E1, E2, E3, E11, E13, } \\
\text { E15, E17 }\end{array}$ & 7 \\
\hline Agradar / fidelizar o cliente & E1, E2, E4, E17, E18 & 5 \\
\hline Pressão & E7, E8, E13, E16, E19 & 5 \\
\hline Expectativas dos superiores sobre resultados & E4, E11, E16, E19 & 4 \\
\hline $\begin{array}{l}\text { Questões macroeconômicas (concorrência, políticas } \\
\text { públicas) }\end{array}$ & E6, E9, E10, E14 & 4 \\
\hline Sobrecarga & E7, E8, E13, E16 & 4 \\
\hline (Baixa) qualificação do pessoal & E4, E13, E15 & 3 \\
\hline Empresa familiar & E9, E19 & 2 \\
\hline Promover "espírito de serviço" / vendas & E1, E2 & 2 \\
\hline "Burocracia" administrativa & E3, E8 & 2 \\
\hline Dependência de subordinados & E3 & 1 \\
\hline Conhecimento de legislação & E4 & 1 \\
\hline Horário de trabalho (final de semana, noturno) & E4 & 1 \\
\hline Relação com sindicato & E4 & 1 \\
\hline
\end{tabular}

Fonte: Dados da pesquisa.

O relacionamento com subordinados foi considerado positivo pela maior parte dos gerentes. Alguns perceberam que ele era, ao mesmo tempo, bom e complicado. No cotidiano, a conduta de gerentes e subordinados se pautava no apoio mútuo, coleguismo, incentivo à comunicação fluida, à participação e à transparência, o que não impedia, no entanto, que problemas ocorressem. A Tabela 7 permite visualizar as respostas dadas. 
Tabela 7. Respostas a "relacionamento com subordinados"

\begin{tabular}{l|l|c}
\hline Respostas a "relacionamento com subordinados" & \multicolumn{1}{|c|}{ Entrevistados } & $\begin{array}{c}\text { Total de } \\
\text { entrevistados }\end{array}$ \\
\hline Bom / muito bom / ótimo / tranqüilo / cordial & $\begin{array}{l}\text { E2, E3, E6, E7, E8, E10 } \\
\text { E11, E12, E13, E14, E15, } \\
\text { E17, E19 }\end{array}$ & 14 \\
\hline Apoio mútuo (profissional e/ou pessoal) & $\begin{array}{l}\text { E1, E4, E7, E8, E12, E14, } \\
\text { E15, E16, E17, E18 }\end{array}$ & 10 \\
\hline Promoção de comunicação / diálogo & $\begin{array}{l}\text { E3, E4, E5, E8, E11, E12, } \\
\text { E14, E15, E16, E17 }\end{array}$ & 10 \\
\hline Difícil / complicado & E4, E8, E9, E13, E17 & 5 \\
\hline Promoção de participação & E2, E5, E8, E11, E12 & 5 \\
\hline Transparência em ações e decisões & E1, E6, E8, E12 & 4 \\
\hline Promoção de políticas motivacionais & E5, F7 & 2 \\
\hline $\begin{array}{l}\text { Incentivo ao desenvolvimento pessoal e/ou } \\
\text { profissional }\end{array}$ & E9, E17 & 1 \\
\hline Incentivo ao cumprimento de metas & E5 & 2 \\
\hline
\end{tabular}

Fonte: Dados da pesquisa

Agradar ao subordinado e cobrá-lo quanto ao desempenho de suas funçōes constitui-se um dilema vivido na função gerencial. Observe:

(...) mas agradar eu sei que eu não agrado todo mundo, até porque eu não estou aqui pra tornar-me agradável para os funcionários, eu tô aqui pra que eles tenham o trabalho (...) nós somos o elo entre o capital e o trabalho (E4). Não reclamam não, a pesquisa de clima da minha empresa é uma das melhores que a [empresa] tem, tranqüilo (...) (E14).

Meu relacionamento é normal, eu exijo disciplina deles, exijo que a hierarquia seja mantida, meu relacionamento com eles é normal (E15).

Ao mesmo tempo, o gerente percebe que o empregado é um sujeito complexo e que seu âmbito de controle não é total, principalmente em se tratando dos resultados organizacionais.
(...) como que está a sua vida além do trabalho, porque eu acho que isso é muito importante e reflete diretamente na qualidade desenvolvida (E8). Primeiro, eu não os vejo como subordinados, eu os vejo como seres humanos; segundo, eu os vejo como cidadãos, e terceiro, eu os vejo como profissionais. Obedecendo a essa trilogia, você é capaz de viver bem com qualquer pessoa, obviamente respeitando as limitaçōes, mas provocando sempre a possibilidade de as pessoas superarem sua capacidade, suas limitaçōes (E9). Você ter que mandar já por natureza, já gera um certo... já é antipático (E13). (...) acho que a gente tem que ser correto com as pessoas, pra gente exigir das pessoas. (...) acho que na área humana não tem regras (E17).

Olha, subordinados é uma palavra assim muito forte, eu diria que são mais os meus amigos de trabalho (...) tenho um bom relacionamento de amizade, porém sabendo impor o respeito, certo? $\mathrm{E}$ isso é o ponto que eu acho fundamental (E17).

No que diz respeito ao relacionamento com os superiores, a maioria dos gerentes afirmou pautar suas relações pelo diálogo, cordialidade e transparência. O incentivo e a cobrança quanto ao cumprimento de metas se fizeram presentes de uma forma bem clara: os gerentes contribuem diretamente para que as metas sejam cumpridas e são periodicamente cobrados nesse sentido. A Tabela 8 resume as respostas recorrentes a essa pergunta.

Um comentário merece destaque em função da clareza e objetividade com que foi colocado pelo entrevistado. Ele foi o único a considerar seu relacionamento com a chefia "explicitamente" melhor que com seus subordinados, em função de algo (não revelado) que teria acontecido no passado.

Vou falar de uma forma bem simples. Com meus superiores é melhor. Por que é melhor? Por causa do nível, do nível de formação, de instrução, de berço, entendeu? Você pega um funcionário hoje, dependendo do que você está chamando a atenção dele, é capaz dele te responder com um palavrão, e o meu diretor ou minha diretora jamais falariam uma coisa assim, você entendeu? Então, com o superior é melhor, dentro deste ponto de vista. Mas não deixa de ter dificuldades, né? Não significa que é uma relação a mil maravilhas, mas tem dificuldades também, mas é pouca, eu acho que melhor do que com os meus subordinados em função desse caso que eu falei (E13).

Porém, o fato de a relação com os superiores espelhar as relações com os subordinados foi explicitado em outras entrevistas, como, por exemplo:

Na realidade, esse trabalho que eu faço com minha equipe reflete o trabalho que o meu superior faz comigo, né? (E8). 
Tabela 8. Respostas a "relacionamento com superiores"

\begin{tabular}{l|l|c}
\hline \multicolumn{1}{c|}{ Respostas a "relacionamento com superiores" } & \multicolumn{1}{|c|}{ Entrevistados } & $\begin{array}{c}\text { Total de } \\
\text { entrevistados }\end{array}$ \\
\hline Promoção de comunicação / diálogo & $\begin{array}{l}\text { E1, E2, E4, E5, E6, E8 E9, } \\
\text { E10, E11, E12, E13, E14, }\end{array}$ & 14 \\
\hline Bom / muito bom / ótimo / tranqüilo / cordial & $\begin{array}{l}\text { E3, E4, E6, E7, E8, E11, E11, } \\
\text { E12, E13, E14, E15, E19 }\end{array}$ & 13 \\
\hline Transparência em ações e decisões & $\begin{array}{l}\text { E1, E2, E4, E6, E8, E9, } \\
\text { E11, E14, E16, E17, E18 }\end{array}$ & 11 \\
\hline $\begin{array}{l}\text { Incentivo / cobrança quanto ao cumprimento de } \\
\text { metas }\end{array}$ & E5, E7, E12, E17, E18 & 5 \\
\hline Apoio mútuo (profissional e/ou pessoal) & E1, E3, E9, E12 & 4 \\
\hline Autonomia & E7, E15 & 2 \\
\hline Difícil / complicado & E13, F17 & 2 \\
\hline Promoção de participação & E8 & 1 \\
\hline
\end{tabular}

Fonte: Dados da pesquisa.

Quando perguntados sobre os conflitos que viviam no exercício de sua função, a maior parte dos entrevistados referiu-se a questões ligadas à integração de interesses diversificados, à variedade de problemas característicos de um empreendimento no setor de hotelaria, ao gerenciamento de pessoas, ao serviço ao cliente e ao cumprimento de metas. Na Tabela 9 podem-se visualizar detalhadamente as respostas dadas.

Algumas frases chamam a atenção para a pressão que os gerentes sofrem em seu dia-a-dia a partir dos referidos conflitos. Observe:

É um leão por dia que a gente tem matar pra consegui ter um resultado bom (E1).

É conciliar mesmo a necessidade do empregado com a necessidade da empresa (risos). (...) Nós, na primeira impressão, nós somos até um pouco terroristas mesmo de falar: - olha, no próximo final de semana é o aniversário do seu filho, então... Mas a pessoa entra consciente daquilo que está sendo esperado dela. E nós temos que tentar também olhar muito o lado do funcionário, é um objetivo da empresa de estar sempre ao lado do funcionário (E4).
Um hotel, o turismo e a hotelaria, é serviço, e serviço você está dependente do ser humano e não da máquina, isso é um grande problema ou, talvez, a grande virtude do nosso negócio. Então você tem dentro do dia-a-dia circunstâncias onde o ser humano por não ser, graças a Deus, não ser infalível, de ser falível, de cometer erros, de cometer equívocos, enfim, de avaliar mal determinadas circunstâncias, é passivo de criar situaçōes constrangedoras, situaçōes complicadas em relação ao cliente. São tantas coisas que acontecem dentro do hotel que não dá pra enumerá-las. Agora, o que no nosso negócio é fundamental, é que tenha bom senso, que tenha equilíbrio, que tenha... veja sempre que do outro lado existe um ser humano, e não simplesmente um cifrão, isso facilita bastante o dia-a-dia (E9).

E os resultados dessas divergências de opiniões e interesses, em termos de relacionamento com clientes, podem ser avaliados como desastrosos.

Aquilo traz conflito pra gente, é grande, tá? Chega casos da gente chegar, inclusive, a perder cliente por pequenos detalhes, tá? (E7).

E em função de um problema desse gerou uma série de outras discussōes, com o horário de verão mudando, qual horário seria, qual horário não seria. Ela chegou a levantar a mão pra mim, tive que segurar a mão dela, tive que pedir a ela calma, tive que falar com o esposo dela, levar ela pro quarto pra ela descansar e tal, depois a gente conversa, entendeu? Então, assim, e isso desde a minha relação com o hóspede, com o meu diretor, e a minha relação com o meu subordinado. Cada dia é uma coisa, a mulher tem TPM, homem eu sei lá o que que tem, mas tem dia que também está impaciente. (...) Mas os problemas e os conflitos de um modo geral são um mínimo (E13).

No entanto, ocupar a gerência implica o desenvolvimento de habilidades que, em outros cargos, nem sempre são exigidas na mesma escala.

O problema maior é que você acaba se envolvendo também emocionalmente com as situações de cada um de seus empregados. Esse talvez seja o problema maior, tá? Cada um te traz um problema, você acaba sendo um confessor, ok? (E19).

A última pergunta direcionada para os gerentes foi a seguinte: "Se você achasse a lâmpada do gênio e ele lhe concedesse três pedidos, no seu ambiente de trabalho, o que você mudaria, tiraria, acrescentaria etc., enfim, quais seriam seus três desejos?". O intuito dessa pergunta era dar espaço ao gerente para que ele falasse sobre suas idéias em torno da empresa, seus processos, atores sociais envolvidos e, sobretudo, sobre si mesmo. Outro aspecto importante foi a possibilidade que a pergunta abriu no que diz respeito à reafirmação e/ou à negação de informações dadas anteriormente, ou seja, a expor contradições. 
Tabela 9. Respostas a "conflitos vividos no exercício da função gerencial"

\begin{tabular}{l|l|c}
\hline $\begin{array}{l}\text { Respostas a “conflitos vividos no exercício da } \\
\text { função gerencial" }\end{array}$ & \multicolumn{1}{|c}{ Entrevistados } & $\begin{array}{c}\text { Total de } \\
\text { entrevistados }\end{array}$ \\
\hline $\begin{array}{l}\text { Conciliar interesses (empregado x empregador; } \\
\text { cliente x hotel, entre áreas do hotel) }\end{array}$ & $\begin{array}{l}\text { E2, E4, E8, E10, E11, E12, } \\
\text { E15, E16, E18, E19 }\end{array}$ & 11 \\
\hline Variedade / especificidade dos problemas & $\begin{array}{l}\text { E2, E3, E6, E7, E8, E9, E10, } \\
\text { E11, E13 }\end{array}$ & 8 \\
\hline $\begin{array}{l}\text { Problemas / conflitos / baixa qualificação / } \\
\text { resistências entre o pessoal }\end{array}$ & $\begin{array}{l}\text { E3, E4, E10, E12, E15, } \\
\text { E17, E19 }\end{array}$ & 7 \\
\hline Servir o cliente & E6, E7, E9, E11, E12, E13 & 6 \\
\hline Cumprimento de metas & E1, E2, E4, E10 & 4 \\
\hline $\begin{array}{l}\text { Questões macroeconômicas (concorrência, } \\
\text { políticas públicas, mercado retraído) }\end{array}$ & E1, E1 & 2 \\
\hline Horário de trabalho x família & E5 & 1 \\
\hline
\end{tabular}

Fonte: Dados da pesquisa.

Em um primeiro ordenamento das respostas somaram-se 26 desejos variados, dos quais se denota a variedade de fatores que compõem o trabalho desses gerentes, mas que também constituem pontos de pressão sobre eles. Em seguida elas foram reordenadas de acordo com os aspectos e os atores sociais que contemplavam, conforme consta na Tabela 10.

Algumas colocações merecem destaque. A importância de empregados qualificados e motivados foi um ponto recorrente nas entrevistas. No entanto, a autonomia para lidar com eles é algo que foi explicitado de várias formas.

Eu (...) colocaria mais mão-de-obra, nós trabalhamos com um quadro bastante reduzido (...) visando à obtenção de lucro (E12).

Em terceiro lugar, eu mandaria embora os nós-cegos, os funcionários ruins de serviço, os que não se enquadram, né? E promoveria os bons funcionários! (E15).

Parece que autonomia e autoridade não vêm conjugadas com responsabilidade, inerentes ao cargo de gerência. Outros espelham, no seu local de trabalho, a autonomia e o status que, de fato, não têm. Observe o comentário:
Tabela 10. Aspectos e atores sociais envolvidos nas respostas relacionadas a "desejos profissionais no exercício da função gerencial"

\begin{tabular}{l|l|c}
\hline $\begin{array}{l}\text { Respostas a “desejos profissionais no exercício } \\
\text { da função gerencial" }\end{array}$ & \multicolumn{1}{|c|}{ Entrevistados } & $\begin{array}{c}\text { Total de } \\
\text { entrevistados }\end{array}$ \\
\hline $\begin{array}{l}\text { Melhorias que envolvem empregados (qualifica- } \\
\text { ção, remuneração, motivação, comunicação, } \\
\text { redução de conflitos etc.) }\end{array}$ & $\begin{array}{l}\text { E1, E2, E3, E4, E6, E7, E8, } \\
\text { E10, E11, E12, E13, E14, } \\
\text { E15, E16, E18, E19 }\end{array}$ & 16 \\
\hline $\begin{array}{l}\text { Melhoria da estrutura física da empresa (reforma, } \\
\text { criação de área de eventos, sauna, sala de } \\
\text { ginástica, benfeitorias na área de segurança etc.) }\end{array}$ & $\begin{array}{l}\text { E1, E2, E5, E7, E10, E12, } \\
\text { E13, E15, E19 }\end{array}$ & 9 \\
\hline $\begin{array}{l}\text { Melhorias que envolvem os clientes (aumento na } \\
\text { demanda, diminuição de ações de "má-fé", maior } \\
\text { polidez, melhoria no relacionamento etc.) }\end{array}$ & E1, E2, E3, E4, E13, E14, & 8 \\
\hline $\begin{array}{l}\text { Ganhos em termos de status, autonomia } \\
\text { Melhoria na relação entre concorrentes }\end{array}$ & E9, E12, E15, E19 & 4 \\
\hline \begin{tabular}{l} 
Investir no "aspecto ambiental" \\
\hline
\end{tabular} & E14 & 1 \\
\hline
\end{tabular}

Fonte: Dados da pesquisa

Porque o espaço que a gente trabalha é... é o espaço suficiente, mas eu queria ter uma sala enorme (...) (E12)

Outro aspecto interessante é que muitos se colocaram na posição do "gênio", ou seja, suas frases começavam com "eu faria", "eu sonho", "eu mudaria”. Outros deixaram bem claro o que pediriam ao gênio, ou seja, aquilo que, de fato, está fora de seu controle e de sua possibilidade efetiva de intervenção. Note-se que um dos entrevistados (E9) se recusou a responder a uma pergunta tão "lúdica", segundo ele.

\section{Entrevistas com os proprietários}

Nas entrevistas com os proprietários, alguns aspectos já relatados por parte dos gerentes foram confirmados. Convém ressaltar que essas duas entrevistas foram, a priori, agendadas com os gerentes. Porém, os proprietários tomaram "a frente", dispensaram os gerentes e se disponibilizaram para conversar acerca das funções gerenciais de seus subalternos. Esse fato, por si só, já é revelador; no entanto, os dados coletados dizem mais. 
Com relação à concepção do papel gerencial, os proprietários sublinharam a importância do relacionamento com os outros funcionários, do atendimento ao cliente com qualidade e do atingimento das metas, ou seja, ter uma visão ampla dos processos na hotelaria. Com relação às especificidades da gerência nesse setor, foi enfatizada a disponibilidade de " 24 horas" por dia, em função da dinâmica do negócio. Um dos proprietários (P2) usou a palavra "escravidão", no sentido de ilustrar a dedicação que é exigida pelo cargo. Isso se relaciona, também, às exigências do cargo. Dentre elas, os proprietários alinharam, além da dedicação, os seguintes pontos: "bom humor, bom senso, energia para trabalhar, raciocínio rápido" (P1), assim como "profissionalismo, educação e atenção com todas as pessoas que o procuram" (P2).

Dentre os pontos positivos de ser gerente naquela empresa, um proprietário (P1) ressaltou o plano de cargos da empresa e a proximidade entre a direção e os funcionários. O outro proprietário (P2) salientou a remuneração acima dos padrões de mercado, a presença atuante da empresa no mercado, o contato com pessoas importantes e o status daí resultante. Já em termos das dificuldades foram apresentadas falhas de comunicação em virtude da qualificação (baixa) dos empregados voltados para a operação do negócio. Outros aspectos abordados relacionaram-se às dificuldades em lidar diretamente com os clientes, e à exclusividade de dedicação que a hotelaria exige.

No que tange às relações com os subordinados, os proprietários acreditavam ser boas (P1), pautadas por confiança e cumplicidade, rumo aos objetivos da empresa, principalmente no que diz respeito à satisfação do cliente (P2). Já na relação com os superiores, ou seja, com eles próprios, as respostas foram instigantes. Observe:

Boa... boa. Manda quem pode, obedece quem tem juízo (P1).

O outro proprietário apenas frisou que ele era "o dono". Essas falas, somadas à não-permissão de que os próprios gerentes dissertassem sobre seu trabalho, revelam um contexto de autoritarismo e de baixa autonomia que vai ao encontro de outros depoimentos dos gerentes entrevistados.

Com relação aos conflitos vividos na função gerencial, os dois proprietários concordaram no que diz respeito à sobrecarga e à pressão no trabalho. Um deles (P2) frisou que era praticamente impossível atender a todas as demandas em um só momento. O outro também foi explícito nesse sentido:

O dia é muito pequeno, 24 horas é pouco; tinha que ser mais, pra dar conta de fazer tudo que tem que fazer, esse é o grande problema (P1.)
Por fim, se eles tivessem achado a "lâmpada do gênio", os desejos que queriam ver concretizados relacionavam-se ao aumento da demanda e à diminuição do número de concorrentes. O comentário de um deles reforça algumas percepções anteriores. Observe:

Cliente, cliente e cliente... o resto eu dou conta. Põe cliente aqui dentro e o resto é por minha conta; eu só preciso de cliente, eu num preciso de mais nada. Tendo cliente aqui dentro... eu mais os meus funcionários, é nossa obrigaçāo atendê-los bem (P1).

\section{Considerações finais}

Seguindo a linha proposta no início do artigo, as considerações serão alinhadas em termos de milícias, malícias e delícias da função gerencial.

No que diz respeito às milícias dessa função, foram explicitadas as dificuldades diárias que os gerentes enfrentam no setor de hotelaria, englobando os desafios, a sobrecarga e a pressão a que estão sujeitos. Observou-se uma certa uniformidade nos depoimentos, a qual não foi percebida nas duas primeiras perguntas. O papel gerencial parece não estar claro para os entrevistados, ou, pelo menos, não na sua amplitude e profundidade. Como se pôde notar, cada respondente possuía uma concepção, dando ênfase a um determinado aspecto da função. Isso denota uma fraca ou fragmentada identidade gerencial, fato discutido em outras pesquisas no Brasil, como as realizadas por Melo $(1995,1999)$. As especificidades dessa função na hotelaria foram ressaltadas, principalmente em termos da disponibilidade, do se fazer presente, ou melhor, da dedicação que o gerente deve ter por conta da dinâmica do próprio negócio e da proximidade com os clientes. Apenas um gerente não concordou com esse último aspecto, o que é perfeitamente compreensível em se tratando de um motel; neste, o distanciamento é uma questão normalmente vista como central. Porém, questiona-se em que medida o gerente, na sua ação cotidiana, tem colaborado para o fortalecimento e para o enfraquecimento de seu espaço e de seu escopo de trabalho.

Já entre as malícias, o lidar com empregados (menos qualificados) e com clientes (categorizados como menos cordiais ou mais exigentes) impõe ao gerente ajustes complexos, e num exíguo espaço de tempo. "Jeito”, “jeitinho" ou "jogo de cintura" foram expressōes recorrentes nas falas dos entrevistados, tanto dos mais experientes como dos menos, tendo em vista a variedade de contingências que foram salientadas. Assim, engendrar as dimensões sublinhadas por Motta (1995) nos níveis organizacional, interpessoal e individual torna-se um ponto 
Tabela 4. Respostas a "principais exigências na função gerencial na empresa"

\begin{tabular}{l|c|c}
\hline $\begin{array}{l}\text { Respostas a "principais exigências na função } \\
\text { gerencial na empresa" }\end{array}$ & Entrevistados & $\begin{array}{c}\text { Total de } \\
\text { entrevistados }\end{array}$ \\
\hline Resultado & E1, E10, E17, E18 & 4 \\
\hline Atendimento ao cliente & E12, E17, E18 & 3 \\
\hline Qualidade & E6, E17, E18 & 3 \\
\hline Sensibilidade e flexibilidade & E13, E14 & 2 \\
\hline Disponibilidade, humildade e criatividade & E3, E15 & 2 \\
\hline $\begin{array}{l}\text { Formação superior e domínio de língua } \\
\text { estrangeira }\end{array}$ & E4, E16 & 2 \\
\hline Conhecimento das áreas da empresa & E11, E19 & 2 \\
\hline Capacidade de liderança & E8, E11 & 2 \\
\hline Decisão & E1 & 1 \\
\hline Andamento dos processos & E1 & 1 \\
\hline Controle das contas & E2 & 1 \\
\hline $\begin{array}{l}\text { Bom senso, conhecimento e vivência } \\
\text { com pessoas }\end{array}$ & E5 & 1 \\
\hline Conhecer os hóspedes e empregados & & 1 \\
\hline Comprometimento com a ética & E9 & 1 \\
\hline
\end{tabular}

Fonte: Dados da pesquisa.

As respostas, na maior parte, revelaram como principais exigências, o alcance dos resultados, a satisfação do cliente, a qualidade dos serviços (relacionada à satisfação do cliente), além de algumas características e habilidades pessoais que devem ser alcançadas. Observe as falas que se seguem:

(...) ela quer o quê? Ela quer bom serviço, boa seleção de pessoal, certo? Ou ocupação e lucros (E19).

A ocupação do hotel e a exigência da clientela, né ? (E10).
Em relação aos aspectos positivos, a principal "delícia" apontada pelos gerentes foi a autonomia. O discurso foi recorrente em $50 \%$ dos casos, seguido do acesso à diretoria e da satisfação dos clientes. Em relação a algum ponto positivo quanto aos empregados, apenas um gerente se referiu ao fato de lidar com pessoas diferentes - incluindo empregados e clientes; outro mencionou investimentos na área de recursos humanos.

Os depoimentos abaixo ilustram os principais pontos positivos.

É, eu tenho autonomia, e sinto que sou uma pessoa muito prestigiada pelos diretores, entendeu? Então, isso me satisfaz, assim, profundamente, eu sou uma pessoa que tenho autonomia para decidir aqui dentro seja o que for: demissão de funcionário, admissão, mudanças nas empresas. E eu gosto do prestígio de ser uma pessoa de confiança da empresa. Eu sinto isso (E15).

(...) é uma empresa que te dá muita liberdade, que tem um relacionamento muito bom, sabe? E que foca muito a área de recursos humanos, de pessoal, né? Está sempre fazendo avaliaçōes de clima, está sempre fazendo avaliação de desempenho, investindo no potencial dos funcionários, isso é tudo muito bom (E14).

E, na Tabela 5, podem-se visualizar as respostas dadas pelos entrevistados. Com relação às dificuldades que enfrentavam no exercício de suas funções, a lista dos gerentes foi extensa, porém com vários pontos de tangência, conforme se pode verificar na Tabela 6 .

A visão dos empregados como parte de uma grande equipe prevaleceu e, daí, as questões decorrentes. Nesse sentido destacam-se os seguintes os comentários:

Porque eles, pra mim, são vendedores internos, então provar isso todo dia é um desafio também (El).

(...) você depende muito de uma equipe, então, às vezes, a pessoa está triste, está invocada, está com problema (E3).

As pessoas são muito resistentes a mudanças, então você promover mudanças, e manter essas mudanças de rotina, de procedimentos, de comportamentos, "são muito difíceis, muito difíceis" (E15).

Aspectos burocráticos da empresa também foram ressaltados, cabendo aqui mais as disfunções do que, efetivamente, a funcionalidade que a burocracia weberiana pressupõe.

(...) As dificuldades que um gerente encontra hoje, no meu caso pelo menos, é só aquela ligada ao turismo, nas outras questões burocráticas, funcionais e mecânicas do trabalho não tem dificuldade, é uma coisa muito simples, é uma coisa muita simples e você procura ser o mais prático possível, não tem segredo nenhum (E6). 
decisivo. Nesse sentido, a formação acadêmica é um aspecto nevrálgico no setor pesquisado, tendo em vista tanto o nível de profundidade (raso) com que alguns entrevistados trataram certas questões que envolvem seu trabalho diário, como as afirmações recursivas de baixa qualificação de pessoal e das consequeencias que dela decorrem

Por fim, as delícias relacionadas à função gerencial referem-se à autonomia, à liberdade, ao acesso à direção, ao status, ao prestígio, enfim, ao poder, sendo que este último denota relações ambíguas e controversas, tanto no caso dos gerentes como no dos proprietários. Dessa maneira, outras pesquisas podem ser realizadas, contemplando pontos como dificuldades, contradições, identidade, subjetividade etc. dos gerentes, porém articulando-as com os aspectos positivos (mesmo que transitórios) dessa função, tanto nas relações que se travam no ambiente interno como no ambiente externo das organizações.

\section{Referências bibliográficas}

ARAÚJO, C. M. 2003. Ética e qualidade no turismo no Brasil. São Paulo: Atlas.

BARDIN, L. 1979. Análise de conteúdo. Lisboa: Ediçōes 70.

BARNARD, C. 1971. As funçōes do executivo. São Paulo: Atlas.

BRAVERMAN, H. 1981. Trabalho e capital monopolista. Rio de Janeiro: Zahar.

CASTELLI, G. 2001. Administração hoteleira. Caxias do Sul: eDuCs.

COZBY, P. C. 2003. Métodos de pesquisa em ciências do comportamento. São Paulo: Atlas.

DEMO, P. 2002. Complexidade e aprendizagem: a dinâmica não linear do conhecimento. São Paulo: Atlas.

DRUCKER, P. 1967. O gerente eficaz. Rio de Janeiro: LTC.

FAYOL, H. 1990. Administração industrial e geral. São Paulo: Atlas.

GUERRIER, Y. 2000. Comportamento organizacional em hotéis e restaurantes. São Paulo: Futura.

HILL, L. A. 1993. Novos gerentes: assumindo uma nova identidade. São Paulo: Makron Books.

KATZ, R. 1986. As habilitaçōes de um administrador eficiente. Coleção Harvard de Administração. Vol. 1, p.57-92. São Paulo: Nova Cultural,

LAVILLE, C. \& DIONE, J. 1999. A Construção do saber: Manual de metodologia da pesquisa em ciências humanas. Porto Alegre: Artes Médicas Sul; Belo Horizonte: Editora UFMG.

LIKERT, R. 1971. Novos padrões de administração. São Paulo: Pioneira.

MELO, M. C. O. L. 1995. O grau de participação e autonomia dos gerentes na empresa: dificuldade e mudanças. In: Revista Tendências do Trabalho, São Paulo, n. 249, p. 17-24, maio.

1999. O gerente e a função gerencial nas organizaçōes pós-reestruturação produtiva. Encontro Nacional de Estudos do Trabalho, VI, Anais... São Paulo: ABEt.
MINAYO, M. C. de S. 1992. O Desafio do conhecimento: pesquisa qualitativa em saúde. São Paulo - Rio de Janeiro: HUCITEC - ABRASCO.

MINTZBERG, H. 1986. Trabalho do executivo: o folclore e o fato. Coleção Harvard de Administração. Vol. 3, p. 5-37. São Paulo: Nova Cultural.

MORGAN, G. 1996. Imagens da organização. São Paulo: Atlas.

MOTTA, P. R. 1995. Gestão contemporânea: a ciência e a arte de ser dirigente. Rio de Janeiro: Record.

QUIVY, R. \& CAMPENHOUDT, L. V. 1998. Manual de investigação em ciências sociais. Lisboa: Gradiva.

RICHARDSON, R. J. et al. 1999. Pesquisa social: métodos e técnicas. São Paulo: Atlas.

TAYLOR, F. W. 1970. Princípios de administração científica. São Paulo: Atlas.

TRIVIÑOS, A. N. S. 1987. Introdução à pesquisa em ciências sociais. São Paulo, Atlas.

WEBER, M. 1982. Ensaios de sociologia. Rio de Janeiro: LTC.

Recebido em: 18/07/2005 (1 $1^{\mathrm{a}}$ versão) e 24/08/2005 ( $2^{\mathrm{a}}$ versão)

Aprovado em: 19/09/2005. 